\title{
Synthesis of nitrogen heterocycles via $\alpha$-aminoalkyl radicals generated from $\alpha$-silyl secondary amines under visible light irradiation $\dagger$
}

Cite this: Chem. Commun., 2014 50,8900

Received 23rd April 2014, Accepted 12th June 2014

DOI: $10.1039 / \mathrm{c} 4 \mathrm{cc} 03000 a$

www.rsc.org/chemcomm

\author{
Kazunari Nakajima, Mai Kitagawa, Yuya Ashida, Yoshihiro Miyake* $\ddagger$ and \\ Yoshiaki Nishibayashi*
}

\begin{abstract}
We have succeeded in the visible light-mediated synthetic use of $\alpha$-aminoalkyl radicals derived from $\alpha$-silyl secondary amines toward addition to $\alpha, \beta$-unsaturated carbonyl compounds. The resulting $\gamma$-aminocarbonyl compounds are converted into $\gamma$-lactams and pyrroles in a one-pot process.
\end{abstract}

Five-membered nitrogen heterocycles such as $\gamma$-lactams and pyrroles are found in various natural products and pharmaceuticals. ${ }^{1,2}$ Construction of these skeletons in a simple and efficient manner is one of the most important topics in synthetic organic chemistry. In this context, the development of a novel synthetic approach for $\gamma$-aminocarbonyl compounds composed of a secondary or primary amine moiety plays a pivotal role because a rapid 5-exocyclization between amine and carbonyl groups gives the corresponding nitrogen heterocycles. ${ }^{1}$

Construction of $\gamma$-aminocarbonyl skeletons by the addition of $\alpha$-aminoalkyl radicals derived from secondary amines to $\alpha, \beta$-unsaturated carbonyl compounds under the photoinduced electron transfer conditions is a potentially useful strategy to access the corresponding nitrogen heterocycles. ${ }^{3}$ However, in these reaction systems, a large amount of $N$-alkylation products was usually observed due to the formation of aminyl radicals by oxidation of secondary amines (Scheme $1 \mathrm{a})^{4,5}$ or direct thermal aza-Michael addition, ${ }^{6}$ where the desired $\gamma$-aminocarbonyl compounds were obtained only in low yields. ${ }^{3}$ As a result, successful examples for synthetic utilization of $\alpha$-aminoalkyl radicals under $\mathrm{UV}^{3,7}$ or visible light ${ }^{8,9}$ irradiation have been strictly limited to the use of tertiary amine derivatives. These results indicate that the generation and utilization of $\alpha$-aminoalkyl radicals derived from secondary amines are quite difficult.

Institute of Engineering Innovation, School of Engineering, The University of Tokyo, Yayoi, Bunkyo-ku, Tokyo, 113-8656, Japan. E-mail: ynishiba@sogo.t.u-tokyo.ac.jp $\dagger$ Electronic supplementary information (ESI) available. CCDC 992086. For ESI and crystallographic data in CIF or other electronic format see DOI: 10.1039/ c4cc03000a

\# Present address: Department of Applied Chemistry, Graduate School of Engineering, Nagoya University, Furo-cho, Chikusa-ku, Nagoya, 464-8603, Japan.
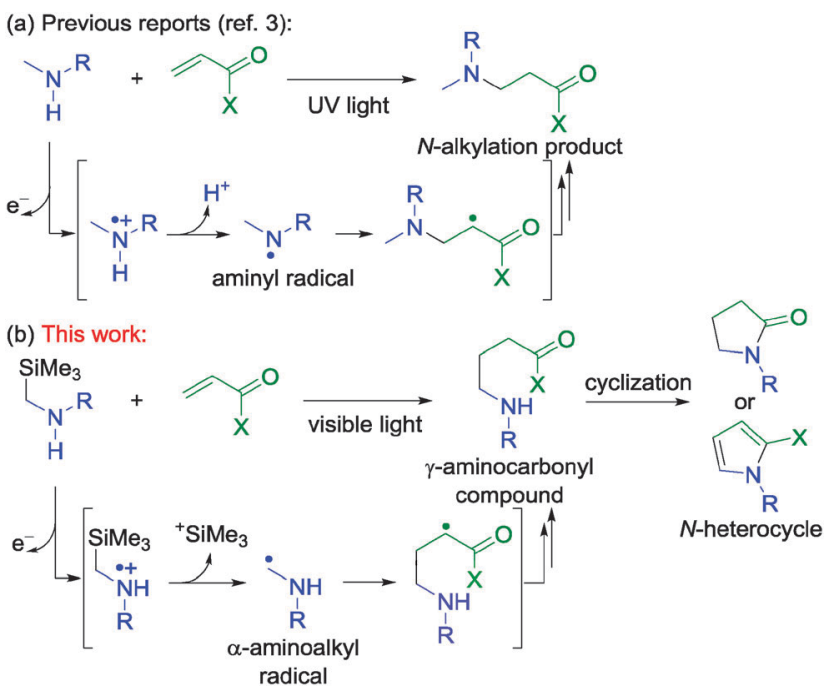

Scheme 1 Photoreactions of secondary amines via (a) aminyl radicals and (b) $\alpha$-aminoalkyl radicals.

Hence, we have envisaged the use of $\alpha$-silylamines as substrates because dissociation of the $\alpha$-C-Si bond of the radical cations occurs readily, which is considered to be suitable for selective formation of $\alpha$-aminoalkyl radicals over aminyl radicals (Scheme $1 \mathrm{~b}$ ). ${ }^{10,11}$ In fact, we have recently succeeded in the synthetic utilization of $\alpha$-aminoalkyl radicals generated from $\alpha$-silyl tertiary amines in the presence of visible light-photoredox catalysts. ${ }^{8,12}$ In the course of our study, we have disclosed visible light-mediated synthetic utilization of $\alpha$-aminoalkyl radicals generated from $\alpha$-silyl secondary amines toward the addition to $\alpha, \beta$-unsaturated carbonyl compounds, where the produced $\gamma$-aminocarbonyl compounds are converted into the corresponding $\gamma$-lactams and pyrroles in simple one-pot procedures. The preliminary results are described here.

Initial investigations of one-pot synthesis of $\gamma$-lactams were conducted using $\mathrm{N}$-(trimethylsilylmethyl)aniline (1a) and diethyl benzylidenemalonate (2a) as substrates (Table 1). In the presence of $1 \mathrm{~mol} \%$ of $[\mathbf{4 a}]\left[\mathrm{BF}_{4}\right]$, the reaction of $1 \mathrm{a}$ with 1.2 equiv. of $2 \mathrm{a}$ was carried out in $N$-methylpyrrolidone (NMP) under visible light 
Table 1 Reactions of $N$-(trimethylsilylmethyl)aniline (1a) with diethyl benzylidenemalonate $(\mathbf{2} \mathbf{a})^{a}$

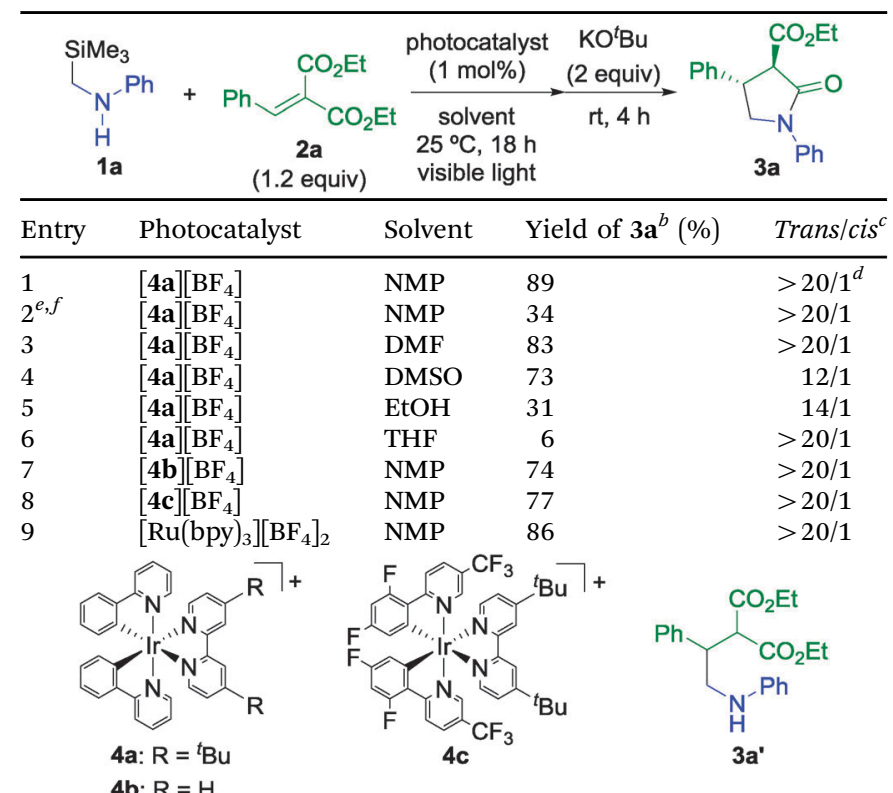

${ }^{a}$ All reactions of $1 \mathrm{a}(0.25 \mathrm{mmol})$ with $2 \mathrm{a}(0.30 \mathrm{mmol})$ were carried out in the presence of a photocatalyst $(0.0025 \mathrm{mmol})$ in solvent $(2.5 \mathrm{~mL})$ under $14 \mathrm{~W}$ white LED illumination at $25{ }^{\circ} \mathrm{C}$ for $18 \mathrm{~h}$. Then, the resulting mixture was treated with $\mathrm{KO}^{t} \mathrm{Bu}(0.50 \mathrm{mmol})$ at room temperature for 4 h. ${ }^{b}$ Isolated yield. ${ }^{c}$ The isomeric ratio was determined by ${ }^{1} \mathrm{H}$ NMR of the crude products. ${ }^{d}$ The isomeric ratio of the isolated 3a is $14 / 1$. ${ }^{e}$ Without treatment with $\mathrm{KO}^{t} \mathrm{Bu} .{ }^{f} 3 \mathbf{a}^{\prime}$ is obtained in $58 \%$ yield.

illumination using a $14 \mathrm{~W}$ white LED at $25{ }^{\circ} \mathrm{C}$ for $18 \mathrm{~h}$. After the photoreaction, treatment of the resulting reaction mixture with 2 equiv. of $\mathrm{KO}^{t} \mathrm{Bu}$ afforded $N$-phenyl-3-ethoxycarbonyl-4-phenyl2-pyrrolidone (3a) in $89 \%$ yield (Table 1, entry 1 ). In the absence of base, uncyclized product ( $\left.3 \mathbf{a}^{\prime}\right)$ was obtained in $58 \%$ yield along with $3 \mathrm{a}$ in $34 \%$ yield (Table 1 , entry 2 ). These results indicate that addition of base is important to obtain the $\gamma$-lactam in a high yield. When reactions were carried out in other polar solvents such as $N, N$-dimethylformamide (DMF) and dimethylsulfoxide (DMSO), 3a was obtained in lower yields (Table 1, entries 3 and 4). Ethanol and tetrahydrofuran (THF) were not effective solvents in this reaction system (Table 1, entries 5 and 6). Use of other iridium complexes ([4b] $]\left[\mathrm{BF}_{4}\right]$ and $\left.[\mathbf{4 c}]\left[\mathrm{BF}_{4}\right]\right)$ and ruthenium(II) tris(2,2'-bipyridyl) complex ([Ru(bpy $\left.\left.)_{3}\right]\left[\mathrm{BF}_{4}\right]_{2}\right)$ as photocatalysts gave 3a in slightly lower yields (Table 1, entries 7-9). Separately, we confirmed that the photoreaction did not proceed at all in the absence of photocatalysts or visible light illumination.

Next, we investigated reactions of various $\alpha$-silylamines (1) with $2 a$ (Table 2). Use of $\alpha$-silylamines bearing an electron-withdrawing or donating group on the benzene ring afforded the corresponding products in excellent yields (Table 2, entries 1-5). Introduction of a naphthyl group instead of a phenyl ring was successful to give $\mathbf{3 g}$ in $75 \%$ yield (Table 2 , entry 6 ). Dialkylamine derivative $\mathbf{1 h}$ was also applicable to this reaction system to give the corresponding products in $44 \%$ yields (Table 2, entry 7 ). The use of an $\alpha$-aminoethyl radical generated from 1-(trimethylsilyl)ethyl amine (1i) gave the corresponding tri-substituted $\gamma$-lactam (3i) in $62 \%$ yield (Table 2, entry 8 ). Unfortunately, when a primary amine derivative
Table 2 Reactions of $\alpha$-silyl secondary amines (1) with diethyl benzylidenemalonate $(2 \mathrm{a})^{a}$

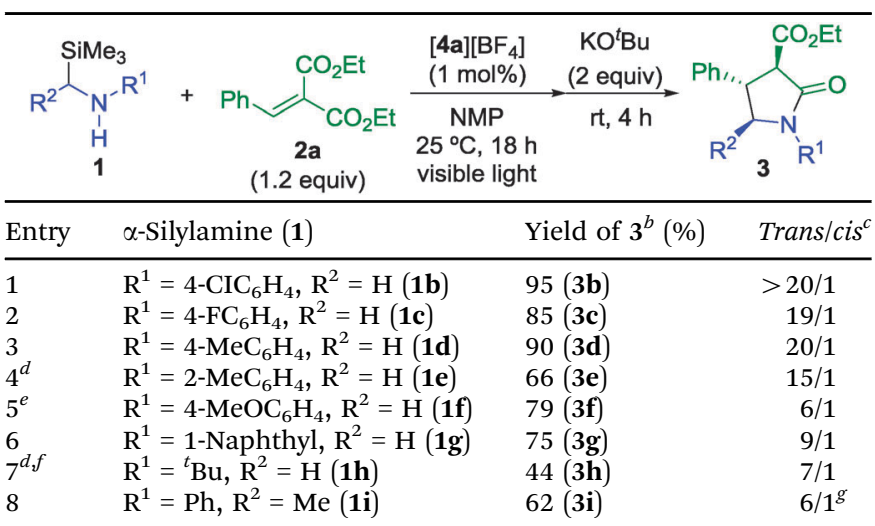

${ }^{a}$ All reactions of $\mathbf{1}(0.25 \mathrm{mmol})$ with $2 \mathrm{a}(0.30 \mathrm{mmol})$ were carried out in the presence of $[4 \mathrm{a}]\left[\mathrm{BF}_{4}\right](0.0025 \mathrm{mmol})$ in NMP $(2.5 \mathrm{~mL})$ under $14 \mathrm{~W}$ white LED illumination at $25{ }^{\circ} \mathrm{C}$ for $18 \mathrm{~h}$. Then, the resulting mixture was treated with $\mathrm{KO}^{t} \mathrm{Bu}(0.50 \mathrm{mmol})$ at room temperature for $4 \mathrm{~h}$. ${ }^{b}$ Isolated yield. ${ }^{c}$ The isomeric ratio was determined by ${ }^{1} \mathrm{H}$ NMR of the isolated products. ${ }^{d}$ Treatment with $\mathrm{KO}^{t} \mathrm{Bu}$ was done at $100{ }^{\circ} \mathrm{C}$ for $17 \mathrm{~h}$. ${ }^{e}$ For $48 \mathrm{~h}$ of photoreaction. ${ }^{f} \mathbf{1 h}(0.30 \mathrm{mmol})$ and $2 \mathrm{a}(0.25 \mathrm{mmol})$ were used. ${ }^{g}$ The ratio of two major isomers.

(trimethylsilylmethyl)amine and an amide derivative $\mathrm{N}$-(trimethylsilylmethyl)acetamide were used as substrates, no formation of the corresponding products was observed.

Reactions of $N$-(trimethylsilylmethyl)aniline (1a) with a variety of $\alpha, \beta$-unsaturated esters (2) were examined (Table 3). Use of $\alpha, \beta$-unsaturated esters bearing various aromatic and alkyl groups gave the corresponding products in high yields (Table 3, entries 1-7). Introduction of a cyano group instead of an ester group was successful to give $\mathbf{3 q}$ in $81 \%$ yield (Table 3 , entry 8 ). When ethyl acrylate ( $2 \mathbf{j}$ ) was used, $3 \mathbf{r}$ was obtained in $47 \%$ yield (Table 3 , entry 9). Tetra-substituted

Table 3 Reactions of $N$-(trimethylsilylmethyl)aniline (1a) with $\alpha, \beta$-unsaturated esters $(\mathbf{2} \mathbf{a})^{a}$

\begin{tabular}{|c|c|c|c|c|}
\hline & ${ }_{\text {(1.2 equiv) }}^{\mathrm{R}^{2}} \mathrm{CO}_{2}$ & 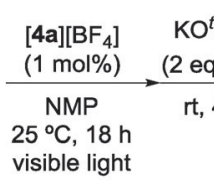 & $\mathrm{R}^{2^{2}}$ & $\begin{array}{l}=0 \\
\mathrm{Ph}\end{array}$ \\
\hline Entry & $\alpha, \beta$-Unsaturated ester & & $\begin{array}{l}\text { Yield } \\
\text { of } 3^{b}(\%)\end{array}$ & Trans/cis ${ }^{c}$ \\
\hline 1 & $\mathrm{R}^{1}=4-\mathrm{CIC}_{6} \mathrm{H}_{4}, \mathrm{R}^{2}=\mathrm{H}$ & $\mathrm{R}^{3}=\mathrm{CO}_{2} \mathrm{Et}(2 \mathbf{b})$ & $79(\mathbf{3 j})$ & $>20 / 1$ \\
\hline 2 & $\mathrm{R}^{1}=4-\mathrm{MeC}_{6} \mathrm{H}_{4}, \mathrm{R}^{2}=\mathrm{I}$ & $\mathrm{R}^{3}=\mathrm{CO}_{2} \mathrm{Et}(2 \mathrm{c})$ & $79(3 \mathbf{k})$ & $20 / 1$ \\
\hline 3 & $\mathrm{R}^{1}=3-\mathrm{MeC}_{6} \mathrm{H}_{4}, \mathrm{R}^{2}=\mathrm{I}$ & $\mathrm{R}^{3}=\mathrm{CO}_{2} \mathrm{Et}(\mathbf{2 d})$ & $62(31)$ & $>20 / 1$ \\
\hline 4 & $\mathrm{R}^{1}=4-\mathrm{MeOC}_{6} \mathrm{H}_{4}, \mathrm{R}^{2}=$ & $\mathrm{I}, \mathrm{R}^{3}=\mathrm{CO}_{2} \mathrm{Et}(\mathbf{2 e})$ & $81(3 \mathbf{m})$ & $20 / 1$ \\
\hline 5 & $\mathrm{R}^{1}=4-\mathrm{PhC}_{6} \mathrm{H}_{4}, \mathrm{R}^{2}=\mathrm{H}$ & $\mathrm{R}^{3}=\mathrm{CO}_{2} \mathrm{Et}(\mathbf{2 f})$ & $61(3 n)$ & $14 / 1$ \\
\hline 6 & $\mathrm{R}^{1}=2$-Naphthyl, $\mathrm{R}^{2}=$ & $\mathrm{R}^{3}=\mathrm{CO}_{2} \mathrm{Et}(2 \mathrm{~g})$ & $61(30)$ & $19 / 1$ \\
\hline 7 & $\mathrm{R}^{1}={ }^{n} \operatorname{Pr}, \mathrm{R}^{2}=\mathrm{H}, \mathrm{R}^{3}=$ & $\mathrm{O}_{2} \mathrm{Et}(2 \mathbf{h})$ & $79(3 \mathbf{p})$ & $11 / 1$ \\
\hline $8^{d}$ & $\mathrm{R}^{1}=\mathrm{Ph}, \mathrm{R}^{2}=\mathrm{H}, \mathrm{R}^{3}=$ & $\mathrm{N}(2 \mathrm{i})$ & $81(3 q)$ & $8 / 1$ \\
\hline 9 & $\mathrm{R}^{1}=\mathrm{R}^{2}=\mathrm{R}^{3}=\mathrm{H}(2 \mathbf{j})$ & & $47(3 r)$ & - \\
\hline 10 & $\mathrm{R}^{1}=\mathrm{R}^{2}=\mathrm{Me}, \mathrm{R}^{3}=\mathrm{CC}$ & t $(2 \mathbf{k})$ & $77(3 \mathrm{~s})$ & - \\
\hline
\end{tabular}

${ }^{a}$ All reactions of $1 \mathrm{a}(0.25 \mathrm{mmol})$ with $2(0.30 \mathrm{mmol})$ were carried out in the presence of $[4 a]\left[\mathrm{BF}_{4}\right](0.0025 \mathrm{mmol})$ in NMP $(2.5 \mathrm{~mL})$ under $14 \mathrm{~W}$ white LED illumination at $25{ }^{\circ} \mathrm{C}$ for $18 \mathrm{~h}$. Then, the resulting mixture was treated with $\mathrm{KO}^{t} \mathrm{Bu}(0.50 \mathrm{mmol})$ at room temperature for $4 \mathrm{~h}$. ${ }^{b}$ Isolated yield. ${ }^{c}$ The isomeric ratio was determined by ${ }^{1} \mathrm{H}$ NMR of the isolated products. ${ }^{d}$ Treatment with $\mathrm{KO}^{t} \mathrm{Bu}$ was done at $100{ }^{\circ} \mathrm{C}$ for $17 \mathrm{~h}$. 
alkene $2 \mathbf{k}$ was also applicable to give the corresponding $\gamma$-lactam (3s) in $77 \%$ yield (Table 3 , entry 10 ).

The success in synthesis of $\gamma$-lactams prompted us to investigate other nitrogen heterocycles such as pyrroles. We have designed $\alpha, \beta$-unsaturated ketones as substrates for the construction of a pyrrole ring. When the reaction of $1 \mathbf{a}$ with an $\alpha, \beta$-unsaturated ketone derivative (5) was examined under similar reaction conditions to the $\gamma$-lactam synthesis, dihydropyrrole (6) was obtained in $64 \%$ yield (Scheme $2 \mathrm{a}$ ). Encouraged by this result, we have successfully developed one-pot synthesis of pyrroles by oxidation of dihydropyrroles (Scheme 2b). After photoreactions of $\alpha$-silyl secondary amines (1a and 1i) with 5, subsequent treatment of the resulting mixture with 2 equiv. of 2,3-dichloro-5,6-dicyano-1,4-benzoquinone (DDQ) at room temperature for $30 \mathrm{~min}$ gave the corresponding tri- and tetrasubstituted pyrroles ( $7 \mathbf{a}$ and $7 \mathbf{b}$ ) in high yields.

To obtain mechanistic insight, some additional experiments were carried out. At first, the quantum yield of the reaction of 1a with 2 a was determined to be 0.13 . The value is in the common range of the photoredox reactions which proceed by a sequential redox process. ${ }^{8}$ Next, we monitored the photoreaction of $\mathbf{1 a}$ with $\mathbf{2 a}$ by GC-MS because isolation of the primary products without an aqueous work-up was not possible due to the high boiling point of NMP. GC-MS analyses indicate that the reaction mixture includes hexamethyldisiloxane and $\mathbf{3} \mathbf{a}^{\prime}$ (see Table 1 for the structure of $3 \mathbf{a}^{\prime}$ ). This result shows that the trimethylsilyl group was captured by adventitious water ${ }^{8,10}$ and $\mathbf{3} \mathbf{a}^{\prime}$ is the primary product in the reaction system. Separately, we carried out the reaction of $\mathbf{1 a}$ with $2 \mathbf{a}$ in the presence of a small amount of water $\left(\mathrm{NMP} / \mathrm{H}_{2} \mathrm{O}=\right.$ $25 / 1$ ), where $3 \mathrm{a}$ was obtained in $86 \%$ yield. This result indicates that the additional water did not affect the yield of $\gamma$-lactam.

Based on the experimental results, the reactions are considered to proceed via a reaction pathway similar to the previously reported sequential redox pathway, as shown in Scheme $3 .^{8}$ At first, single electron oxidation of $\alpha$-silyl secondary amines 1 by a photo-excited catalyst ( ${ }^{*}$ cat) occurs. Then, $\alpha$-aminoalkyl radicals (A) are formed along with generation of trimethylsilyl cations. ${ }^{10}$ The trimethylsilyl cation is captured by adventitious water in the reaction system to give hexamethyldisiloxane and protons. Addition of $\mathbf{A}$ to $\alpha, \beta$-unsaturated carbonyl compounds 2 affords the corresponding radical intermediates $(\mathbf{B})$. The reduction of $\mathbf{B}^{13}$ by a reduced catalyst $\left(\text { cat }^{-}\right)^{14}$ and subsequent protonation give $\gamma$-aminocarbonyl compounds (C) as primary products. Subsequently, base-mediated
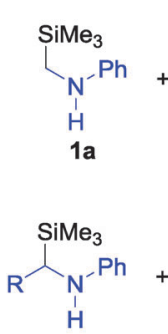

$1 \mathrm{a}(\mathrm{R}=\mathrm{H})$

$1 \mathrm{i}(\mathrm{R}=\mathrm{Me})$
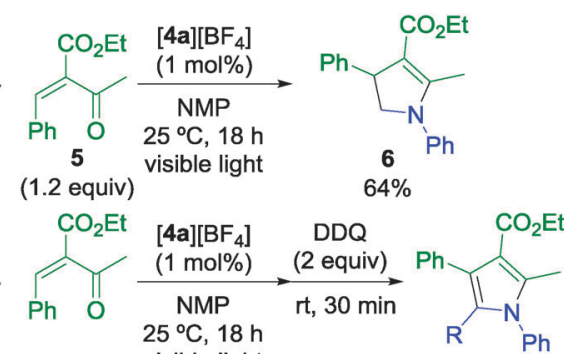

$7 a(R=H): 72 \%$

$7 b(R=M e): 55 \%$ (a)

Scheme 2 One-pot syntheses of dihydropyrrole (6) and pyrroles (7a and 7b).

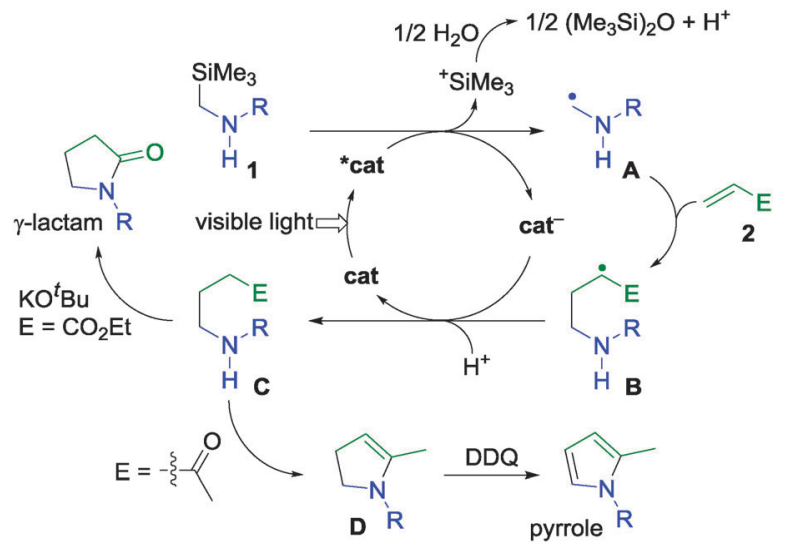

Scheme 3 Plausible reaction pathways.

cyclization of $\mathbf{C}\left(\mathrm{E}=\mathrm{CO}_{2} \mathrm{Et}\right)$ affords $\gamma$-lactams, while oxidation of dihydropyrroles (D) formed by dehydration condensation of $\mathbf{C}$ $\left(\mathrm{E}=\mathrm{COCH}_{3}\right)$ gives pyrroles.

In summary, we have developed a novel reaction system for generation and utilization of $\alpha$-aminoalkyl radicals derived from secondary amines. The $\alpha$-aminoalkyl radicals were successfully applied toward addition to $\alpha, \beta$-unsaturated carbonyl compounds and subsequent cyclization into nitrogen heterocycles such as $\gamma$-lactams and pyrroles. We believe that the method described here provides a useful approach for syntheses of various nitrogen heterocycles, which are useful in pharmacological science. Further investigations on scope of substrates and mechanistic details are now under way.

We thank the Funding Program for Next Generation WorldLeading Researchers (GR025) and Grants-in-Aid for Scientific Research (Nos. 26288044, 26620075, 26105708, and 26870120) from the Japan Society for the Promotion of Science (JSPS) and the Ministry of Education, Culture, Sports, Science and Technology of Japan (MEXT).

\section{Notes and references}

1 (a) M. B. Smith, in Science of Synthesis, ed. S. M. Weinreb, Theme, Stuttgart, 2005, p. 647; (b) D. StC. Black, in Science of Synthesis, ed. G. Maas, Theme, Stuttgart, 2001, p. 441.

2 (a) B. Nay, N. Riache and L. Evanno, Nat. Prod. Rep., 2009, 26, 1044; (b) A. Lebedev, Chem. Heterocycl. Compd., 2007, 43, 673; (c) H. Hoffmann and T. Lindel, Synthesis, 2003, 1753; (d) D. O'Hagan, Nat. Prod. Rep., 2000, 17,435 .

3 (a) S. Das, J. S. D. Kumar, K. Shivaramayya and M. V. George, J. Photochem. Photobiol., A, 1996, 97, 139; (b) S. Das, J. S. D. Kumar, K. Shivaramayya and M. V. George, J. Chem. Soc., Perkin Trans. 1, 1995, 1797; (c) R. C. Cookson, S. M. deB. Costa and J. Hudec, Chem. Commun., 1969, 753.

4 (a) M. Schmittel and A. Burghart, Angew. Chem., Int. Ed. Engl., 1997, 36, 2550; (b) F. D. Lewis and P. E. Correa, J. Am. Chem. Soc., 1984, 106, 194; (c) F. D. Lewis, B. E. Zebrowski and P. E. Correa, J. Am. Chem. Soc., 1984, 106, 187; (d) R. W. Fessenden and P. Neta, J. Phys. Chem., 1972, 76, 2857.

5 A. G. Fallis and I. M. Brinza, Tetrahedron, 1997, 53, 17543.

6 (a) J. Wang, P. Li, P. Y. Choy, A. S. C. Chan and F. Y. Kwong, ChemCatChem, 2012, 4, 917; (b) D. Enders, C. Wang and J. X. Liebich, Chem. - Eur. J., 2009, 15, 11058.

7 (a) D. Harakat, J. Pesch, S. Marinković and N. Hoffmann, Org. Biomol. Chem., 2006, 4, 1202; (b) A. Bauer, F. Westkämper, S. Grimme and T. Bach, Nature, 2005, 436, 1139; (c) E. S. de Alvarenga, C. J. Cardin and J. Mann, Tetrahedron, 1997, 53, 1457. 
8 (a) Y. Miyake, Y. Ashida, K. Nakajima and Y. Nishibayashi, Chem. - Eur. J., 2014, 20, 6120; (b) Y. Miyake, K. Nakajima and Y. Nishibayashi, Chem. Eur. J., 2012, 18, 16473; (c) Y. Miyake, Y. Ashida, K. Nakajima and Y. Nishibayashi, Chem. Commun., 2012, 48, 6966; (d) Y. Miyake, K. Nakajima and Y. Nishibayashi, J. Am. Chem. Soc., 2012, 134, 3338.

9 (a) H. Zhou, P. Lu, X. Gu and P. Li, Org. Lett., 2013, 15, 5646; (b) L. R. Espelt, E. M. Wiensch and T. P. Yoon, J. Org. Chem., 2013, 78, 4107; (c) S. Zhu, A. Das, L. Bui, H. Zhou, D. P. Curran and M. Rueping, J. Am. Chem. Soc., 2013, 135, 1823; (d) X. Ju, D. Li, W. Li, W. Yu and F. Bian, Adv. Synth. Catal., 2012, 354, 3561; (e) P. Kohls, D. Jadhav, G. Pandey and O. Reiser, Org. Lett., 2012, 14, 672; $(f)$ A. McNally, C. K. Prier and D. W. C. MacMillan, Science, 2011, 334, 1114.

10 (a) D. W. Cho, U. C. Yoon and P. S. Mariano, Acc. Chem. Res., 2011 44, 204; (b) U. C. Yoon and P. S. Mariano, Acc. Chem. Res., 1992, 25, 233.
11 (a) D. Lenhart and T. Bach, Beilstein J. Org. Chem., 2014, 10, 890; (b) E. Meggers, E. Steckhan and S. Blechert, Angew. Chem., Int. Ed. Engl., 1995, 34, 2137; (c) G. Pandey, G. D. Reddy and G. Kumaraswamy, Tetrahedron, 1994, 50, 8185; (d) G. Pandey, G. Kumaraswamy and U. T. Bhalerao, Tetrahedron Lett., 1989, 30, 6059.

12 (a) D. M. Schultz and T. P. Yoon, Science, 2014, 343, 985; (b) C. K. Prier, D. A. Rankic and D. W. C. MacMillan, Chem. Rev., 2013, 113, 5322; (c) T. Koike and M. Akita, Synlett, 2013, 2492; (d) J. Xuan and W.-J. Xiao, Angew. Chem., Int. Ed., 2012, 51, 6828; (e) J. M. R. Narayanam and C. R. J. Stephenson, Chem. Soc. Rev., 2011, 40, 102.

13 J. M. Kern and P. Federlin, Tetrahedron Lett., 1977, 18, 837.

14 M. S. Lowry, J. I. Goldsmith, J. D. Slinker, R. Rohl, R. A. Pascal Jr., G. G. Malliaras and S. Bernhard, Chem. Mater., 2005, 17, 5712. 